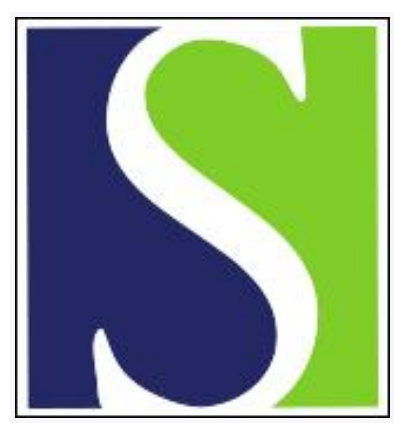

Scand J Work Environ Health 1983;9(2):83-88

https://doi.org/10.5271/sjweh.2419

Issue date: Apr 1983

Reproductive hazards in the workplace. Development of epidemiologic research.

by Landrigan PJ, Melius JM, Rosenberg MJ, Coye MJ, Binkin NJ

This article in PubMed: www.ncbi.nlm.nih.gov/pubmed/6648424

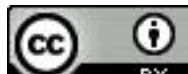




\title{
Reproductive hazards in the workplace
}

\section{Development of epidemiologic research}

\author{
by Philip J Landrigan, MD, MSc, James M Melius, MD, \\ Michael J Rosenberg, MD, MPH, Molly J Coye, MD, Nancy J Binkin, MD
}

\begin{abstract}
LANDRIGAN PJ, MELIUS JM, ROSENBERG MJ, COYE MJ, BINKIN NJ. ReproLANDRIGAN PJ, MELIUS JM, ROSENBER environ health 9 (1983) 83-88. Application of the techniques of epidemiology and clinical toxicology has accelerated study of the reproductive effects of toxic chemical and physical exposures in the workplace. Three examples of work in progress are included in the present communication. The first concerns 1,2-dibromo3-chloropropane, a known cause of male sterility, which continues to be used as a nematocide in Hawaii. Occupational exposures of Hawaiian agricultural workers to airborne 1,2-dibromo-3-chloropropane are mainly in the range of parts per billion. A prospective study of pineapple field workers has been undertaken to evaluate sperm counts and morphology before, during, and after 1,2-dibromo-3-chloropropane application. To date, no sperm count depression is evident at this level of exposure. The second example involves a cluster of seven spontaneous abortions in female office workers exposed to video display terminals. The cluster has been analyzed with the use of fetal life tables. Excess incidence was confirmed $(p=0.0045)$, but no etiology was determined. The findings may have been due to chance. The third example pertains to male chemical workers manufacturing diaminostilbene, an optical brightener, and the workers' reported sexual impotence. Impotence was confirmed in 7 of 29 workers by questionnaire and suggested for another 7 . Serum testosterone analyses found depressed values $(<300 \mathrm{mg} / \mathrm{ml})$ in 8 of 28 exposed workers. The luteinizing hormone and follicular stimulating hormone levels were generally normal.
\end{abstract}

Key terms: dibromochloropropane, DBCP, epidemiology, male infertility, optical brighteners, sperm counts, video display terminals (cathade ray tubes).

Each year several hundred new chemical compounds are added to the 30,000 compounds and 4 million mixtures, formulations, and blends already in commercial use in the Western countries (11). Exposures to chemical compounds can produce a spectrum of adverse reproductive effects including mutation, chromosome changes, impotence, sperm abnormalities, subfecundity, early or late fetal loss, stillbirth, decreased birth weight, altered sex ratio, birth defects, and childhood malig-

1 Division of Surveillance, Hazard Evaluations and Field Studies, National Institute for Occupational Safety and Health, Cincinnati, Ohio, United States.

Reprint requests to: Dr PJ Landrigan, National Institute for Occupational Safety and Health, 4676 Columbia Parkway, Cincinnati, OH 45226, USA. nancies $(2,6,9,10)$. Study of these problems requires close collaboration between the disciplines of epidemiology, toxicology, and clinical medicine. In this report we describe several recent investigations of occupational reproductive hazards which have been undertaken in the United States by the National Institute for Occupational Safety and Health (NIOSH).

\section{Infertility in pesticide workers exposed to 1,2-dibromo-3-chloropropane}

1,2-Dibromo-3-chloropropane, a petrochemical-based nematocide, was produced in California beginning in 1962 . In 1977 , as a result of concern that employment in the manufacture of this chemical was associated with infertility, five 
workers from the manufacturing facility underwent voluntary medical evaluation. All were found to have oligospermia or azoospermia. None had other predisposing causes for infertility, and none had vasectomies.

Further evaluation of male workers employed in 1,2-dibromo-3-chloropropane manufacture found low sperm counts (below 1 million sperm $/ \mathrm{ml}$ ) in 11 nonvasectomized men. These 11 men were compared with 11 co-workers who had sperm counts of $40 \mathrm{million} / \mathrm{ml}$ or greater. A striking association was found between sperm count depression and length of employment. The men with depressed counts had an average exposure of eight years, while those with counts in the normal range had an average employment of less than six months. Workers with depressed sperm counts also had elevated serum levels of luteinizing hormone and follicular stimulating hormone, apparently as a result of their testicular dysfunction (13).

Follow-up studies (14) were conducted on the entire male population of the plant. One hundred and forty-two men were evaluated, of whom 107 had a past history of exposure to the chemical in question and 35 had never been exposed. A significant and striking difference in median sperm counts was noted between the two groups. Of the exposed $13.1 \%$ were azoospermic, and $16.8 \%$ were severely oligospermic. Among the nonexposed $2.9 \%$ were azoospermic, and none were severely oligospermic. Ten workers exposed to 1,2-dibromo-3-chloropropane underwent testicular biopsy. In the most severe cases there was generalized absence of all spermatogenic activity (14).

To evaluate the toxicity of 1,2-dibromo3-chloropropane at lower levels of exposure, NIOSH is conducting a combined industrial hygiene and prospective medical evaluation of agricultural workers exposed in pineapple fields in Hawaii. Industrial hygiene monitoring indicates that most of the field workers' exposures to airborne 1,2-dibromo-3-chloropropane are below $1 \mathrm{ppb}$. However, in some exceptional instances, exposures are much higher, ranging to $1,800 \mathrm{ppb}$.

Medical evaluation has involved three groups of workers at two plantations 35 field workers who apply 1,2-dibromo3 -chloropropane, 27 maintenance workers who repair fumigation tractors, and a reference group of 29 nonexposed plantation workers. Each participant was administered a questionnaire regarding reproductive history, past chemical exposures, and possible confounding factors (eg, alcohol and marijuana consumption). Also three semen specimens were collected from each participant one before the fumigation season, one midway through, and one approximately three weeks after the season. The participation rate was approximately $80 \%$, and it did not differ significantly among the groups.

Preliminary analysis of the medical data indicates that exposure to 1,2-dibromo-3-chloropropane in low concentrations produces no significant effects on sperm count (table 1). The field workers and maintenance men showed a decrease in mean sperm count of 1.0 and 1.1 million $/ \mathrm{ml}$ of semen, repectively, from the pre to postseason, these differences were not however statistically significant. Nonexposed workers showed a mean decline of 1.17 million sperm $/ \mathrm{ml}$ of semen.

Further analyses of these data will evaluate possible associations between the number of hours of 1,2-dibromo-3-chloropropane exposure for each worker during the past season and sperm counts. A previous evaluation of sperm counts in agricultural workers with moderate exposure to 1,2-dibromo-3-chloropropane

Table 1. Mean decline in the sperm count of agricultural workers exposed to dibromochloropropane from the beginning to the end of the pineapple growing season.

\begin{tabular}{lccc}
\hline Category & Number & $\begin{array}{c}\text { Exposure } \\
\text { status }\end{array}$ & $\begin{array}{c}\text { Mean sperm count } \\
\text { decline (count/ml semen) }\end{array}$ \\
\hline Field workers & 35 & Yes & $1,006,000$ \\
Maintenance workers & 27 & Yes & $1,160,000$ \\
Other agricultural workers & 29 & No & $1,172,000$ \\
\hline
\end{tabular}


showed an association between duration of exposure in the preceding year and degree of sperm count depression (4).

\section{Spontaneous abortions among office workers}

In August 1980 a physician at a corporate regional headquarters in the Southwestern United States reported an apparently increased rate of spontaneous abortions among female workers in the firm's computer center. The women were all employed in the accounting department, which is located in a well-lighted, quiet, and air-conditioned building. The accounting department contains 29 video display terminals. During the first week of each month, each woman spent at least $1 \mathrm{~h} / \mathrm{d}$ working at a video display terminal. The use of such terminals during the remainder of the month was less intense.

To evaluate the possible significance of the abortion cluster, investigators from NIOSH and from the Centers for Disease Control administered the workers a questionnaire which determined demographic data, work history, and reproductive history. Interviews were sought with all 69 women currently working in the accounting department. Absentees were also traced. To avoid the bias of selection against women who had carried pregnancies to term and were no longer employed, attempts were made to contact, by mail or telephone, the 23 women who had left employment within the previous 18 months.

Twenty-two pregnancies were found to have occurred over a three-year period in the accounting department. To determine whether or not the frequency of spontaneous abortions among these pregnancies was excessive, fetal life-table analysis was performed for these pregnancies (5). Rates of spontaneous abortions developed from published data were used to generate the expected number of spontaneous abortions. These expected rates were specific for maternal age and week of gestation. To eliminate the problem of nonindependent events from multiple pregnancies in an individual, only first pregnancies occurring during the study period were used in the analysis.
The mean age of the women working in the department was 27.4 years with a range of 18-57 years. All of the women were in excellent health prior to pregnancy. Twelve of the 22 conceptions resulted in normal term births, seven in spontaneous abortions, two in induced abortions, and one in a premature infant who died in the neonatal period.

Life-table analysis considered 19 of the 22 pregnancies: 6 ending in spontaneous abortion, 12 term births, and the 1 premature birth. The seventh spontaneous abortion was not included since the diagnosis of pregnancy was simultaneous with the spontaneous abortion. The two induced abortions were also excluded. Based on the standard rates in the life table, 1.5 spontaneous abortions would have been expected in this population. The probability due to chance of observing six spontaneous abortions in the accounting department was 0.0045 (one-tailed).

The pregnancies resulting in spontaneous abortions showed a definite clustering in time. All seven of the women conceived within a 14-month period (May 1979-June 1980). Only five women who conceived during this period carried pregnancies to term.

No geographic clustering of cases at employees' work or home locations was evident. No association was found with reported infection during pregnancy, nor was there a significant association with history of smoking, alcohol use, medication use, radiography during pregnancy, or maternal illness such as anemia, hypertension or urinary tract infection.

No association between the amount of video display terminal use and adverse pregnancy outcome was evident (table 2). Although working in proximity to video display terminals was associated with a slightly increased relative risk of spontaneous abortion, this difference was not statistically significant.

On follow-up one year after the initial investigation, four new pregnancies were reported. All resulted in term births.

In summary, this investigation documented a temporal cluster of spontaneous abortions in a group of female office workers. No characteristic associated with the adverse outcomes could be determined, and prospective surveillance disclosed no 

Table 2. Relative risk of spontaneous abortion in accounting department employees by video
display terminal exposure, September 1977 - August 1980 a

\begin{tabular}{|c|c|c|c|c|c|}
\hline Characteristic & $\begin{array}{l}\text { Adverse } \\
\text { outcome }\end{array}$ & $\begin{array}{l}\text { Total number of } \\
\text { pregnancies }\end{array}$ & Rate b & $\begin{array}{l}\text { Relative } \\
\text { risk }\end{array}$ & $\begin{array}{c}95 \% \text { confidence } \\
\text { interval }\end{array}$ \\
\hline $\begin{array}{l}\text { Full-time use } \\
\text { Proximity to } \\
\text { video display terminal }\end{array}$ & 2 & 6 & 33 & 0.9 & $0.1-3.5$ \\
\hline $\begin{array}{r}5 \text { feet }(\leq 1.5 \mathrm{~m}) \\
>5 \text { feet }(>1.5 \mathrm{~m})\end{array}$ & $\begin{array}{l}3 \\
4\end{array}$ & $\begin{array}{r}7 \\
13\end{array}$ & $\begin{array}{l}43 \\
31\end{array}$ & $\begin{array}{c}1.4 \\
\cdot\end{array}$ & $0.3-5.1$ \\
\hline
\end{tabular}

a Taken from the manuscript of Binkin et al, which is in preparation.

b Spontaneous abortions per 100 pregnancies.
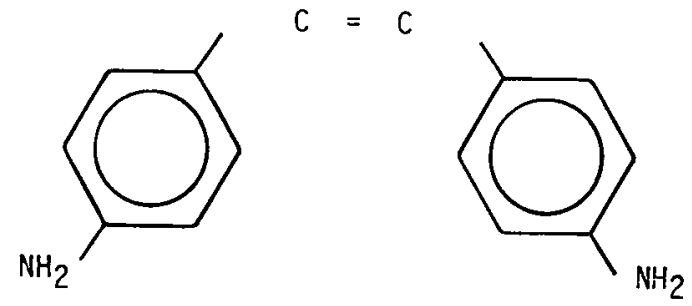

DAS

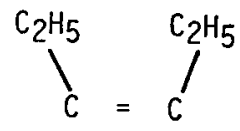
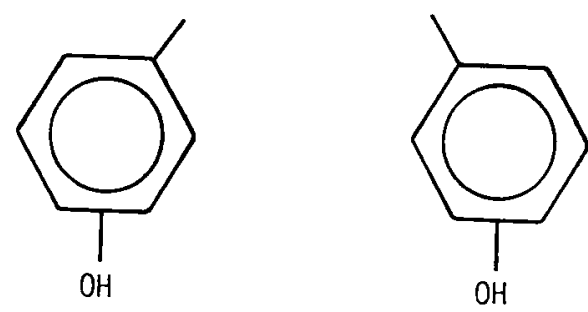

Cis-DES

Fig 1. Chemical structures of diaminostilbene (DAS) and diethylstilbesterol (DES).

continuing problems. The findings may have been due to chance, given that no specific etiology was identified and that, in a sufficiently large number of groups of women, the likelihood is extremely high that at least some groups will have a high rate of adverse pregnancy outcome by chance alone.

Future investigations of reported fetal losses in employed populations will require a stringent search for specific etiologies, as well as development of a method for lifetime comparison of the fertility of exposed workers to nonexposed referents (1). In addition, to increase understanding of the natural history of spontaneous abortions, their frequency must be more precisely defined in relation to such known risk factors as smoking and alcohol use. Systematic surveillance of spontaneous abortions, and in particular of patterns of chromosome aberration in aborted fetuses, may provide a sensitive technique for monitoring environmental and occupational reproductive hazards (7).

\section{Impotence in chemical workers}

In 1981 NIOSH was asked to investigate a report of sexual impotence among male chemical production workers, who were employed in Alabama in the manufacture of diaminostilbene (fig 1), an optical brightener.

The preliminary investigation included a walk-through inspection of the plant and interviews with 39 workers currently or recently employed in the affected area (12). In the interviews impotence was defined as a failure rate of $25 \%$ or greater to achieve erection during sexual intercourse.

Seven $(18 \%)$ of the workers were diagnosed by history as having impotence. In addition another four $(10 \%)$ of the workers reported experiencing some difficulty in sustaining an erection, and another three workers $(8 \%)$ reported a past history of impotence. Thus the total proportion of workers in the affected areas with a history of probable or possible impotence was $36 \%$. The affected workers' 
average age, number of years of employment at the plant, number of years in the area, and history of diabetes, vascular symptoms, drug usage, psychatric disturbances or alcohol consumption were similar to those of the unaffected workers in the same plant area. The affected workers tended to report more paresthesia and genitourinary symptoms. No interviews have, to date, been conducted in other plant departments.

To corroborate the histories of impotence in the workers in the affected area, venous blood samples were obtained for the determination of serum testosterone concentrations. Of the 28 men studied, serum testosterone was subnormal $(<300$ $\mathrm{ng} / \mathrm{ml})$ in eight $(29 \%)$, borderline $(300-$ $350 \mathrm{ng} / \mathrm{ml})$ in four $(14 \%)$, and normal in the remaining $16(57 \%)$.

The serum luteinizing hormone and follicular stimulating hormone levels were also examined and found generally to be normal. However one man had a serum testosterone level in the "female range," and he also had elevated luteinizing hormone and follicular stimulating hormone values compatible with a diagnosis of primarily gonadal failure. Another man had a serum testosterone level that was clearly subnormal and an elevated luteinizing hormone value; his follicular stimulating hormone level was normal.

Further epidemiologic evaluation utilizing blinded interviews of workers in this facility or in other plants with exposure to diaminostilbene will be required for the further evaluation of the possible association of diaminostilbene with male sexual impotence and decreased serum testosterone. In addition toxicologic studies to evaluate possible chemical interactions between diaminostilbene and either diethylstilbesterol or natural estrogens may be of value (fig 1 ).

\section{Discussion}

The evaluation of groups of workers who are experiencing reproductive difficulties or who are exposed to suspect reproductive toxins serves the important function of establishing priorities for larger, more definitive studies. One of the great problems confronting such follow-up studies is, however, the fact that extreme- ly large samples are needed to investigate associations between industrial exposures and most adverse reproductive outcomes. For example, to study a relatively common outcome, spontaneous abortion (which occurs in about $15 \%$ of pregnancies of at least eight weeks' gestation), about 320 pregnancies are needed to detect a doubling in incidence. By the time we consider that $58 \%$ of all women are married, $56 \%$ are fecund (3), and $32 \%$ of all couples are not using some form of birth control (8), an exposed population of over 3,000 workers is required to collect the needed 320 pregnancies. Since studies of such magnitude present formidable logistic problems, it is likely that NIOSH and other national institutes will bear an increasing responsibility for the conduct of major reproductive studies in the $1980 \mathrm{~s}$ and beyond. The Scandanavian nations have recently taken an important step towards the undertaking of such studies by establishing a system for monitoring the reproductive health of its entire regional population. The magnitude of this effort implies that such studies may cross international boundaries, a feature that in future years will assume increasing importance.

Future NIOSH studies of occupational reproductive toxicity will include evaluations of workers exposed to ethylene oxide, ethylene dibromide, glycol ethers, microwave/radiofrequency radiation, and possibly formaldehyde. NIOSH has also established a series of record linkage systems with the National Center for Health Statistics and with various state health departments for the prospective surveillance of occupational reproductive problems.

\section{References}

1. Bakketeig LS, Seigel DG, Sternthal PM. A fetal-infant life table based on single births in Norway, 1967-1973. Am j epidemiol 107 (1978) 216-224.

2. Bloom AD, ed. Guidelines for studies of human populations exposed to mutagenic and reproductive hazards. March of Dimes Birth Defects Foundation, New York, NY 1981

3. Eckhard G. Advanced data from vital and health statistics of the National Center for Health Statistics. National Center for Health Statistics, Hyattsville, Md 1980. (No 24, January 24). 
4. Glass RI, Lyness RN, Mengle DC, Powell KE, Kahn E. Sperm count depression in pesticide applicators exposed to dibromochloropropane. Am i epidemiol 109 (1979) 346-351.

5. Harlap S, Shiono PH, Ramcharan S. A life table of spontaneous abortions and the effects of age, parity, and other variables. In: Hook EG, Porter I, ed. Reproductive loss. Academic Press, New York, NY 1980.

6. Hemminki $K$, Sorsa M, Vainio $H$. Genetic risks caused by occupational chemicals: Use of experimental methods and occupational risk group monitoring in the detection of environmental chemicals causing mutations, cancer, and malformations. Scand $j$ work environ health 5 (1979) 307327.

7. Kline J, Stein Z, Strobino B, Susser M, Warburton D. Surveillance of spontaneous abortions - Power in environmental monitoring. Am $j$ epidemiol 106 (1977)
$345-350$.

8. Mosher WD. Trends in contraceptive practice, United States 1965-76: Vital and health statistics. National Center for Health
Statistics, Hyattsville, Md 1981. (Publication DHHS (PHS) 82-1981, series 23, no 10).

9. Rao KS, Schwetz BA. Reproductive toxicity of environmental agents. Ann rev public health 3 (1982) 1-27.

10. Strobino BR, Kline J, Stein Z. Chemical and physical exposures to parents: Effects on human reproduction and offspring. Early hum dev 1 (1978) $371-399$.

11. US Environmental Protection Agency, Office of Toxic Substances. Core activities of the Office of Toxic Substances (draft program plan). Washington, DC 1976. (EPA publication 560/4-76-005).

12. Wegman DH, Quinn MM. Preliminary report for health hazard evaluation of male sexual dysfunction. National Institute for Occupational Safety and Health, Cincinnati, OH 1981.

13. Whorton D, Krauss RM, Marshall S, Milby TH. Infertility in male pesticide workers. Lancet 2 (1977) 1259-1261.

14. Whorton D, Milby TH, Krauss R, Stubbs HA. Testicular function in DBCP exposed pesticide workers. J occup med 21 (1979) 